\title{
Modul Pembelajaran Berasaskan Projek: Kesan terhadap Pencapaian Teori dalam Projek Tahun Akhir 1 di Kolej Vokasional
}

\author{
Wan Hafiidzull Wan Rashid*, Che Ghani Che Kob, Arman Shah Abdullah \\ Universiti Pendidikan Sultan Idris, Tanjung Malim, Perak Malaysia \\ *Corresponding author, email: cheghani@ftv.upsi.edu.my
}

\begin{abstract}
Abstrak
Pelajar Kolej Vokasional khususnya dalam bidang Teknologi Kejuruteraan Mekanikal dan Pembuatan (TKMP) kurang pencapaian dalam aspek teori terutamanya dalam penulisan berbentuk ilmiah kerana faktor pendekatan pembelajaran secara konvensional. Matlamat kajian ini adalah untuk membangunkan Modul Pembelajaran Berasaskan Projek (M-PBPj) bagi subjek Projek Tahun Akhir 1 (PTA1) dan menilai kesannya terhadap pencapaian teori pelajar. Reka bentuk kajian ini menggunakan kaedah kuantitatif melalui kuasi-eksperimen kumpulan rawatan dan kumpulan kawalan. Kajian ini melibatkan 91 orang pelajar sebagai sampel di sebuah Kolej Vokasional di negeri Perak, Malaysia. Kuasi-eksperimen digunakan dalam kajian kerana kaedah ini mampu menunjukkan kesan penggunaan pemboleh ubah mengikut dua tempoh masa pra dan pasca. Keberkesanan Modul Pembelajaran Berasaskan Projek (M-PBPj) dinilai melalui Ujian-T sampel berpasangan dan sampel tidak berpasangan. Penyelidik mencadangkan supaya penggunaan Modul Pembelajaran Berasaskan Projek (M-PBPj) ini digunakan dalam proses pengajaran dan pembelajaran bagi subjek Projek Tahun Akhir 1 (PTA1) agar dapat meningkatkan pencapaian teori dalam melaksanakan penulisan ilmiah.
\end{abstract}

Kata Kunci: kuasi-eksperimen, pembelajaran berasaskan projek, pencapaian teori, pendidikan teknik dan vokasional, projek tahun akhir 1

How to Cite: Rashid, W. H. W., Kob, C. G. C., \& Abdullah, A. S. (2020). Modul Pembelajaran Berasaskan Projek: Kesan Terhadap Pencapaian Teori Dalam Projek Tahun Akhir 1 di Kolej Vokasional. Journal of Vocational Education Studies, 3(1), 83-92. DOI: https://doi.org/10.12928/joves.v3i1.1409.

\section{PENGENALAN}

Sistem vokasional masih lagi baru diperkenalkan di Malaysia jika dibandingkan dengan negara-negara maju yang lain (Sauffie, 2015; Yunos, 2008). Justeru itu kurikulum yang digubal masih lagi tidak menyeluruh dalam konteks budaya pendidikan di Malaysia kerana kurang data empirikal sebagi rujukan bagi penambahbaikan. Ini melibatkan juga kurikulum dalam KV yang merupakan subset dalam Pendidikan Teknik dan Vokasional (PTV) di Malaysia. Hasil tinjauan awal penyelidik mendapati bahawa wujud masalah dalam pelaksanaan Projek Tahun Akhir 1 (PTA1) yang telah dilaksanakan di Kolej Vokasional (KV) yang merangkumi masalah pencapaian yang sederhana dalam teori kalangan pelajar Teknologi Kejuruteraan Mekanikal dan Pembuatan (TKMP). Pembelajaran dalam PTA1 merangkumi penyediaan kertas cadangan projek dan pelaksanaan pembangunan awal projek. Kajian yang dijalankan oleh Hie, Mahadhir, \& Banggan (2014), juga melihat sisi yang sama dengan para pelajar dalam sistem PTV mempunyai keyakinan diri agak rendah dan kemajuan yang perlahan yang mempengaruhi pencapaian dalam menjalankan projek akhir sekalipun dikawal oleh penyelia.

Pendekatan konvensional yang bergantung kepada pembelajaran berpusatkan guru juga telah menyebabkan hasil pembelajaran dalam PTA1 tidak dapat dicapai sepenuhnya. Selain itu, kaedah konvensional seperti syarahan sukar untuk melihat hasil pembelajaran yang lebih meluas dalam kemahiran generik seperti kemahiran komunikasi dan kerja berpasukan (Othman et al., 2015). Menurut kajian yang melibatkan 160 pelajar semester akhir di Politeknik Port Dickson oleh Jaafar \& Anita (2002) mendapati, kemahiran generik 
pelajar berada dalam tahap yang sederhana. Sehubungan itu, kajian yang dijalankan oleh Matore (2014) di 7 buah politeknik di Malaysia mendapati cabaran utama pelajar dalam PTV adalah takut gagal dalam ujian, bimbang terhadap peperiksaan, berasa malas, dan kurang keyakinan diri. Habók dan Nagy (2016) mencadangkan keperluan kepada panduan tambahan dalam membangunkan instrumen penilaian dalam Pembelajaran Berasaskan Projek (PBPj) untuk lebih efektif.

Justeru itu, Modul PBPj (M-PBPj) yang setara dalam PTA1 perlu diwujudkan kerana menurut Geurts dan Meijers (2009), suasana pembelajaran yang kukuh perlu mempunyai karakter pembelajaran konstraktivis, pelajar melibatkan diri dengan aktiviti kognitif, aktiviti dipantau oleh pengajar, dan penilaian yang boleh mengukur pengetahuan, pemahaman, dan kemahiran. PBPj yang berstruktur juga boleh membuka minat pelajar dalam melaksanakan projek akhir kerana membentuk asas kepada kemahiran kajian dan membentuk pemikiran ingin tahu ke arah kajian (Rambely et al., 2013). Oleh yang demikian, satu kajian perlu dilakukan bagi mengkaji keberkesanan M-PBPj dalam subjek PTA1 TKMP dalam meningkatkan pencapaian dari segi teori.

\section{PEMBELAJARAN BERASASKAN PROJEK (PBPj)}

Pembelajaran Berasaskan Projek (PBPj) memberi definisi maksud yang pelbagai mengikut dapatan dan kajian ahli psikologi dan pengkaji (Buck Institute for Education, 2017). Menurut Buck Institute for Education, PBPj ditakrifkan sebagai kaedah sistematik yang melibatkan pelajar dalam pembelajaran pengetahuan dan kemahiran menerusi proses siasatan lanjutan yang disusun di sekitar kompleks, soalan sahih dan produk dan tugas yang direka dengan teliti.

PBPj merupakan model pengajaran yang menggunakan teknik praktikal berdasarkan prinsip kontruktivis. Kajian menunjukkan adalah lebih baik sekiranya pengajar dapat mengawal interaksi sampel dengan lebih dekat dalam peringkat kumpulan. Melalui cara ini, pengajar dapat mengenal pasti permasalahan dan dapat meningkatkan hasil pembelajaran (Norhafezah et al., 2011). Proses mengawal pelajar dalam konsep projek adalah pengajar bertindak sebagai fasilitator. Bell (2010) pula menyatakan bahawa PBPj adalah pembelajaran berpusatkan pelajar dan pengajar bertindak sebagai fasilitator, penilaian adalah bersifat autentik, pelajar diukur menggunakan rubrik dan pelajar belajar melalui proses yang dilalui. Dapatan ini menjelaskan bahawa PBPj sesuai untuk digunakan sebagai kaedah dalam subjek PTA1 yang perlu melihat hasil pembelajaran pelajar melalui pencapaian akhir semata-mata, tetapi turut mengukur kriteria dalam pembelajaran abad ke-21 seperti kemahiran berkomunikasi dan berkolaborasi.

Sadrina dan Mustapha (2017) turut mendefinisikan PBPj sebagai kaedah pembelajaran yang sistematik, bermula dengan mencari idea, menyelesaikan masalah sebenar, mewujudkan reka bentuk projek, bekerja bersama, dan menghasilkan produk. Melalui definisi ini, pelaksanaan M-PBPj dalam PTA1 mempunyai kekuatan dan kelebihan berbanding kaedah konvensional kerana beliau juga menjelaskan bahawa pelaksanaan PBPj memerlukan modul yang relevan untuk mencapai matlamat pembelajaran. Oleh demikian, definisi PBPj boleh dirumuskan sebagai kaedah pembelajaran berpusatkan pelajar yang sistematik, berprinsipkan konstruktivis, melalui proses siasatan lanjutan, menyelesaikan masalah sebenar, pengajar sebagai fasilitator, bekerjasama, dan menghasilkan produk.

Pembelajaran Konvensional pula (PK) merupakan kaedah pembelajaran yang berpusatkan pengajar atau guru (Ahmad et al., 2015; Alavi, Sail, \& Awang, 2013; Christina \& Kristin, 2016; Herman, 2007; Omar, Taib, \& Basri, 2012; Othman et al., 2015; Yassin, Baharom, \& Yahaya, 2010). Kaedah ini merupakan asas kepada guru atau pengajar dalam pengajaran dan pembelajaran.

Menurut Alavi et al. (2013) kaedah ini sentiasa digunakan oleh pengajar dalam bidang kemahiran seperti dalam PTV dan kurang diberi perhatian terhadap kesan kepada 
pelajar terutamanya dalam pembelajaran yang memerlukan pelajar untuk bekerja sendiri atau pembelajaran berpusatkan pelajar seperti dalam PTA1. Di sini kaedah pembelajaran berpusatkan pelajar tidak berlaku dengan sepenuhnya dan pelajar lebih cenderung untuk menjadi pasif (Omar et al., 2012). Kaedah menyelia dan memantau yang sehala merupakan kaedah yang sering digunakan oleh setiap pengajar atau penyelia projek melalui kaedah pembelajaran konvensional (Rahman et al., 2009). Kaedah ini juga sukar untuk dijadikan penunjuk kepada hasil pembelajaran kerana tidak jelas dalam melihat seperti berkomunikasi dan kerja kumpulan di kalangan pelajar.

Menurut Habók \& Nagy (2016) pendidikan konvensional dan ujian seragam umumnya tidak mematuhi keperluan abad ke-21, yang terdiri daripada keperluan luar tempat kerja dan keperluan dalaman, seperti keperluan intrinsik individu. Di samping itu, terdapat pelbagai pelajar, termasuk pelajar dan pelajar yang berpendapatan rendah yang mempunyai keperluan pendidikan khas, yang arahannya memerlukan kaedah inovatif. Kajian yang dijalankan oleh Yassin et al. (2010) menjelaskan perlunya kepada perubahan dalam kaedah mengajar dalam kalangan pengajar PTV, namun terdapat juga kesukaran kepada perubahan dari fasa konvensional kepada fasa selainnya seperti kaedah PBPj kerana faktor kurang keyakinan dalam proses PBPj. Oleh demikian, kajian ini akan melihat semula kelemahan-kelemahan dalam kaedah konvensional dalam proses pembelajaran PTA1 dan melakukan penambahbaikan terhadap kaedah pembelajaran ini.

\section{MODUL PEMBELAJARAN BERASASKAN PROJEK PTA1(M-PBPj)}

Modul Pembelajaran Berasaskan Projek (M-PBPj) dibangunkan dengan menggunakan model ADDIE. Pembangunan M-PBPj akan melalui peringkat Analisis, Reka Bentuk, Pembangunan, Pelaksanaan, dan Penilaian.

M-PBPj dibangunkan dengan lapan bahagian utama yang meliputi keseluruhan pengetahuan dan amali dalam PTA1. Setiap bahagian mewakili proses-proses utama dalam PTA1 iaitu Pengenalan Kepada Pembelajaran Berasaskan Projek, Projek Tahun Akhir 1 (PTA1), Bab 1: Pengenalan Projek, Bab 2: Tinjauan Literatur, Bab 3: Metodologi Projek, dan Penulisan Ilmiah Cadangan Projek.Terdapat satu bahagian yang memberi pengetahuan kepada pelajar berkaitan PBPj dan lima bahagian merangkumi elemen penulisan, pembentangan, dan penilaian dalam PTA1.

M-PBPj telah mendapat kesahan dari tiga orang pakar dengan memperoleh 88.54 peratus persetujuan. Kebolehpercayaan M-PBPj pula seperti dalam Jadual 1 di bawah.

Jadual 1. Nilai Kebolehpercayaan Alpha Cronbach M-PBPj

\begin{tabular}{clcc}
\hline Bahagian & \multicolumn{1}{c}{ Tajuk } & Alpha Cronbach & Bilangan Item \\
\hline 1 & $\begin{array}{l}\text { Pengenalan Kepada Pembelajaran } \\
\text { Berasaskan Projek }\end{array}$ & 0.821 & 4 \\
2 & Projek Tahun Akhir 1 (PTA1) & 0.716 & 4 \\
3 & Bab 1: Pengenalan Projek & 0.728 & 4 \\
4 & Bab 2: Tinjauan Literatur & 0.801 & 4 \\
5 & Bab 3: Metodologi Projek & 0.706 & 4 \\
6 & Penulisan Ilmiah Cadangan Projek & 0.711 & 4 \\
7 & Pengenalan Kepada PTA2 & 0.753 & 4 \\
& $\quad$ Keseluruhan & 0.748 & 28 \\
\hline
\end{tabular}

\section{REKA BENTUK KAJIAN}

Reka bentuk kajian yang akan dijalankan adalah kuasi eksperimen kerana reka bentuk ini melibatkan penglibatan pelajar dalam kumpulan pembelajaran sedia ada (Clark \& Creswell, 2015). Subjek kajian ini terdiri daripada 91 orang pelajar dalam bidang TKMP di Kolej Vokasional Slim River (KVSR), Perak dan dipilih untuk mewakili populasi yang dikaji. 
Para pelajar yang terlibat telah dipastikan telah menghadiri kuliah pembelajaran PTA1 dan seterusnya intervensi dijalankan bagi kumpulan rawatan. Penyelidik melantik lapan orang pensyarah sebagai fasilitator yang terlebih dahulu diberi latihan tentang proses pembelajaran berasaskan projek. Kertas ujian pencapaian ditadbirkan secara langsung oleh fasilitator yang telah dilantik oleh penyelidik.

Pentadbiran ujian pencapaian teori dilaksanakan mengikut takwim pembelajaran yang sebenar. Para pelajar perlu menjawab kesemua 40 soalan objektif yang telah dirangka oleh penyelidik untuk ujian teori dan mengedarkan sejumlah 93 kertas soalan ujian teori. Soalan ujian ini telah disemak dan disahkan oleh tiga orang pakar bagi tujuan kesahan dan memperoleh 89.33 peratus persetujuan serta telah diuji kebolehpercayaan melalui nilai Kuder-Richarson 20 iaitu 0.74. Sebelum data diproses, data dibersihkan dengan mendapati 91 responden hadir untuk menjawab ujian pra dan pasca. Maka, kadar respons dalam kajian ini adalah sebanyak $97.8 \%$ iaitu memenuhi saranan Johnson dan Christensen (2008) yang menyatakan bahawa, kadar respons yang menghampiri $70 \%$ atau lebih adalah diterima, iaitu sampel kajian dapat mewakili populasi kajian sebenar. Rajah 1 menunjukkan kerangka kajian kuasi eksperimen yang dijalankan secara keseluruhan.

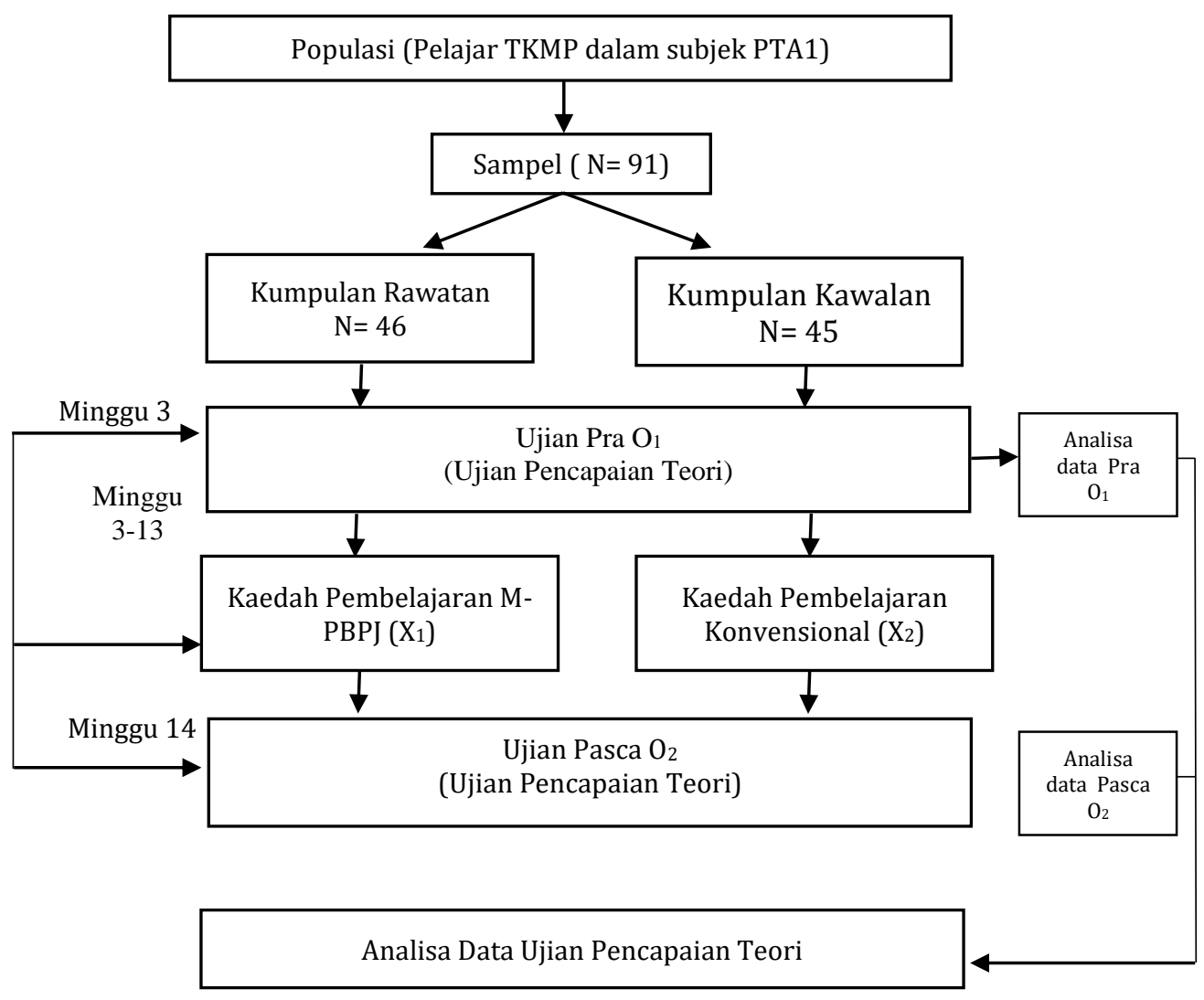

Rajah 1. Kerangka kajian keseluruhan kuasi-eksperimen PTA1

\section{KEPUTUSAN DAN ANALISIS}

Jadual 2 menunjukkan taburan kekerapan sampel kumpulan rawatan dan kawalan untuk skor min dan sisihan piawai ujian pra. Didapati skor min ujian pra teori bagi kumpulan kawalan dan rawatan masing-masing ialah 12.93 dan 12.57. Sisihan piawai untuk kawalan ialah 2.32, manakala untuk rawatan ialah 2.94 dengan markah minimum dan maksimum kawalan ialah 7 dan 18 serta rawatan memperoleh markah minimum dan maksimum 8 dan 19. 
Jadual 2. Statistik Deskriptif Skor Ujian Teori Pra Sampel Kajian Mengikut Kumpulan

\begin{tabular}{lcc}
\hline Ujian Pra & Kumpulan Kawalan & Kumpulan Rawatan \\
\hline $\mathrm{N}$ & 45 & 46 \\
$\mathrm{Min}$ & 12.93 & 12.57 \\
Sisihan Piawai & 2.32 & 2.94 \\
Minimum & 7 & 8 \\
Maksimum & 18 & 19 \\
\hline
\end{tabular}

Ujian normaliti secara statistik pencongan (skewness) dan kutosis (kurtosis) digunakan untuk menentukan normaliti data ujian pencapaian teori bagi membolehkan data diuji menggunakan statistik parametrik. Dalam kajian ini penyelidik menggunakan ujian $\mathrm{t}$ sampel berpasangan dan sampel tidak berpasangan yang merupakan ujian jenis parameterik (Singh, Abdul Ghani, dan Teoh, 2009). Jika data yang diperoleh tidak bertaburan normal, maka ujian statistik Mann Whitney dan Wilcoxon signed-rank yang merupakan ujian yang bukan parametrik perlu digunakan. Data bagi ujian teori untuk ujian pra dan pasca bagi subjek PTA1 dianalisis dengan menggunakan statistik pencongan (skewness) dan kutosis (kurtosis) dan hasil analisis adalah dalam Jadual 4.

Berpandukan julat nilai yang ditetapkan oleh (Kim, 2013), taburan data ujian pra dan pasca dianggap normal kerana nilai bagi pencongan dan kutosis adalah kecil iaitu menghampiri nilai sifar dan berada dalam julat -1.96 dan +1.96 .

Jadual 4. Nilai Pencongan dan Kutosis Ujian Pencapaian Teori Bagi Sampel Kajian

\begin{tabular}{lcc}
\hline Perkara & Ujian Pra & Ujian Pasca \\
\hline Pencongan & .317 & -.074 \\
Kutosis & -.425 & .033 \\
\hline
\end{tabular}

Jadual 5 menunjukkan statistik deskriptif skor min ujian pencapaian teori bagi para pelajar kumpulan rawatan dan kawalan.

Jadual 5. Statistik Deskriptif Skor Min Ujian Pencapaian Teori

\begin{tabular}{llcc}
\hline \multicolumn{2}{c}{ Ujian Teori } & Ujian Pra & Ujian Pasca \\
\hline \multirow{2}{*}{ Skor Min } & Kawalan & 12.93 & 21.02 \\
\cline { 2 - 4 } & Rawatan & 12.57 & 27.54 \\
\hline
\end{tabular}

Jadual 6. Keputusan Ujian-t Sampel Tidak Berpasangan

\begin{tabular}{|c|c|c|c|c|c|}
\hline & $\begin{array}{c}\text { Ujian Levene } \\
\text { Kesetaraan Varians }\end{array}$ & \multicolumn{4}{|c|}{ Kesetaraan Min Untuk Ujian t } \\
\hline & \multirow[t]{2}{*}{$\begin{array}{ll}\mathrm{F} & \text { Signifikan }\end{array}$} & \multirow[t]{2}{*}{$\mathrm{df}$} & \multirow[t]{2}{*}{ Signifikan } & \multicolumn{2}{|c|}{$\begin{array}{c}\text { 95\% perbezaan skala } \\
\text { kepercayaan }\end{array}$} \\
\hline & & & & Had Bawah & Had Atas \\
\hline Pasca & .021 .886 & -7.005 & .000 & -8.371 & -4.672 \\
\hline
\end{tabular}

Jadual 6 menunjukkan keputusan hasil ujian-t sampel tidak berpasangan dengan terdapat perbezaan skor min ujian pencapaian teori kumpulan rawatan $(\mathrm{M}=27.64, \mathrm{SP}=$ 4.525) dengan kumpulan kawalan $(\mathrm{M}=21.02$, $\mathrm{SP}=4.355$; $\mathrm{t}(89)=-7.005, \mathrm{p}=.000)$. Nilai $\mathrm{p}$ kurang .05 menunjukkan terdapat kesan pengaplikasian Modul Pembelajaran Berasaskan Projek (M-PBPj) dan pembelajaran secara konvensional terhadap pencapaian teori pelajar dalam subjek PTA1. 
Jadual 7 menunjukkan statistik deskriptif skor min ujian pencapaian teori bagi pra dan pasca pelajar kumpulan rawatan.

Jadual 7. Statistik Deskriptif Skor Min Ujian Pencapaian Teori Kumpulan Rawatan

\begin{tabular}{lll}
\hline Ujian Teori & Ujian Pra & Ujian Pasca \\
\hline Skor min (M) & 12.57 & 27.54 \\
Sisihan Piawai (SP) & 2.941 & 4.355
\end{tabular}

Jadual 8 menunjukkan keputusan hasil ujian-t sampel berpasangan dengan terdapat perbezaan skor min ujian pencapaian teori kumpulan rawatan $(\mathrm{M}=-14.978, \mathrm{SP}=5.327$; $\mathrm{t}$ $(45)=-19.070, p=.000$ ). Nilai p kurang .05 menunjukkan terdapat kesan pengaplikasian Modul Pembelajaran Berasaskan Projek (M-PBPj) terhadap kumpulan rawatan.

Jadual 8. Keputusan Ujian-t Sampel Berpasangan Hipotesis 4

\begin{tabular}{|c|c|c|c|c|c|c|c|c|}
\hline \multicolumn{9}{|c|}{ Perbezaan Berpasangan } \\
\hline & \multirow[t]{2}{*}{ Min } & \multirow[t]{2}{*}{$\begin{array}{l}\text { Sisihan } \\
\text { Piawai }\end{array}$} & \multirow{2}{*}{$\begin{array}{l}\text { Std. } \\
\text { Ralat } \\
\text { Min }\end{array}$} & \multicolumn{2}{|c|}{$\begin{array}{c}\text { 95\% perbezaan skala } \\
\text { kepercayaan }\end{array}$} & \multirow[t]{2}{*}{$\mathrm{t}$} & \multirow[t]{2}{*}{ df } & \multirow[t]{2}{*}{ Sig. } \\
\hline & & & & Bawah & Atas & & & \\
\hline Pair1 UjianPra-UjianPasca & -14.978 & 5.327 & .785 & -16.560 & -13.396 & -19.070 & 45 & .000 \\
\hline
\end{tabular}

Nilai Cohen d yang diperoleh adalah 0.88 menunjukkan perbezaan antara ujian teori pra dan pasca kumpulan rawatan mempunyai nilai magnitud yang tinggi. Bagi kumpulan kawalan, nilai Cohen d yang diperoleh adalah sederhana iaitu 0.71 .

\section{KESIMPULAN}

See \& Rashid (2015) menyarankan bahawa kaedah PBPj boleh dipraktikkan oleh guru terutamanya dalam bidang teknikal dan vokasional untuk membantu meningkatkan tahap pengetahuan pelajar secara teori. Walau bagaimanapun penggunaan PBPj dalam penguasaan isi kandungan sesuatu subjek seperti PTA1 di Malaysia masih lagi baru jika dibandingkan dengan kajian-kajian dari luar negara seperti yang dijalankan oleh Li (2015) dan Han dan Bhattacharya (2001). Oleh demikian, kajian ini telah membuka dimensi baru bagi perkembangan dalam pedagogi pendidikan khususnya PBPj. Penggunaan PBPj sebagai asas kepada modul bagi subjek PTA1 membolehkan pelajar mengingat asas dalam melakukan penulisan cadangan kajian seterusnya membantu meningkatkan pencapaian dalam subjek ini.

Dalam kajian ini, dapatan data deskriptif mencadangkan secara relatif peningkatan skor min (perbezaan skor min ujian pra dan ujian pasca) bagi kedua-dua kumpulan dengan mencatatkan peningkatan skor min bagi dua tempoh masa. Dapatan kajian inferensi melalui ujian t tidak berpasangan mendapati terdapat perbezaan yang signifikan terhadap skor min ujian teori subjek PTA1 bagi dua tempoh masa kumpulan pembelajaran secara PBPj dan pembelajaran secara konvensional. Ini selari dengan kajian yang dijalankan oleh See dan Rashid (2015) yang menyatakan PBPj boleh meningkatkan tahap pengetahuan pelajar secara teori terutamanya dalam topik vokasional. Perkara ini berlaku kerana PBPj boleh meningkatkan kemahiran penaakulan pelajar dalam pembelajaran (Aziz, Shamsuri, dan Damayanti, 2013). Faktor peningkatan pengetahuan pelajar ini selari dengan tujuan utama pembinaan modul berasaskan PBPj iaitu menyediakan sumber pembelajaran kepada pelajar. Amri, Azman, Kiong,dan Khairudin (2019) turut bersetuju bahawa penggunaan bahan bantuan pengajaran membantu dalam menimbulkan minta dan mendorong untuk terus belajar. Ketersediaan sember pembelajaran yang terhad antaranya menjadi punca kepada kekurangan pengetahuan dari pelajar terutamanya dalam subjek yang abstrak seperti PTA1. Oleh demikian, langkah untuk membina M-PBPj 
adalah selari dengan kehendak PBPj iaitu sumber pembelajaran perlu disediakan oleh pihak pengajar dan hasil dapatan kajian menunjukkan peningkatan positif terhadap kumpulan yang menggunakan pendekatan PBPj.

Selain itu, pengajar juga perlu membantu pelajar dalam membentuk pengetahuan melalui pengalaman. Pembelajaran konstruktivis kognitif menyarankan tindak balas pelajar melalui pengalaman akan membawa kepada pembelajaran. Maka, penggunaan Modul PBPj (M-PBPj) dalam kajian ini ialah sebagai objek untuk membantu proses adaptasi skema baru samada melibatkan asimilasi atau akomodasi. Pelajar di peringkat kolej vokasional terdiri daripada pelajar sederhana berdasarkan kelayakan masuk ke pengajian dan perkara ini penting untuk para pengajar membina perancangan yang bersesuaian dengan tahap penerimaan pembelajaran oleh pelajar. Boleh dikatakan setiap subjek pembelajaran di kolej vokasional adalah perkara baru kepada setiap pelajar. Oleh demikian, pengajar bertanggungjawab dalam membantu pelajar membina pengetahuan terutamanya melalui pengalaman pelajar itu sendiri. Pengajar hanya bertindak sebagai fasilitator dan membuka kepada ruang pembentukan pengalaman pelajar secara kendiri dan berpandu.

Hasil dapatan ujian $t$ berpasangan bagi dua tempoh masa kumpulan pembelajaran secara PBPj turut menggambarkan perbezaan yang signifikan terhadap skor min ujian teori. Perkara ini menyokong teori pembelajaran bermakna yang mengelaskan pembelajaran kepada dua dimensi, iaitu cara maklumat disampaikan dan cara pelajar mengaitkan maklumat ke struktur kognitif sedia ada. Pendekatan secara deduktif diterapkan dalam M-PBPj iaitu pelajar terlebih dahulu diperkenalkan kepada prinsip atau konsep yang terlibat, seterusnya diperkenalkan kepada asas pembentukan prinsip atau konsep tersebut. Penggunaan M-PBPj sebagai medium pendedahan pengetahuan kepada pelajar dilihat mampu memberi kesan yang positif kepada peningkatan pengetahuan pelajar. Penyediaan sumber pembelajaran melalui pembinaan modul dapat memberi peluang kepada setiap pelajar yang terlibat untuk mendapat bahan pembelajaran yang setara. Perkara ini dapat menjamin kesetaraan antara pelajar dan penyampaian pembelajaran daripada pengajar. Jurang pengetahuan antara setiap pelajar dapat dikurangkan melalui penggunaan M-PBPj ini.

Di samping itu, penyelidik melihat kepada saiz kesan (Cohen d) bagi kedua-dua kumpulan bagi memastikan kesan bahan pembelajaran. Nilai saiz kesan antara kumpulan rawatan dan kawalan menunjukkan secara statistik bahawa penggunaan M-PBPj memberi kesan yang tinggi untuk kumpulan rawatan berbanding sederhana bagi kumpulan kawalan dalam meningkatkan pencapaian ujian teori PTA1. Ini selari dengan dapatan kajian yang dilakukan oleh Yeop (2012) yang menyatakan bahawa pendekatan secara PBPj menunjukkan kesan yang positif terhadap pencapaian pelajar berbanding pendekatan secara konvensional.

\section{RUJUKAN}

Ahmad, A., Nordin, M. K., Ali, D. F., \& Nabil, A. (2015). Conducting Hands-On Task in Vocational Education: Teaching Method in Automotive Courses. Journal of Technical Education and Training, 7(1).

Alavi, K., Sail, R. M., \& Awang, A. H. (2013). Image of technical education and vocational training from the perspective of parents and teachers. Journal of Technical Education and Training, 5(1).

Amri, A. N., Azman, M. N. A., Kiong, T. T., \& Khairudin, M. (2019). Keberkesanan Alat Bantu Mengajar (SMART COT) dalam Asas Pembuatan Perabot Sekolah Menengah Kebangsaan Harian Pendidikan Khas Tingkatan Satu. Journal of Vocational Education Studies, 2(1), 23-36. 
Aziz, Z., Shamsuri, S. M., \& Damayanti, L. (2013). Project based learning to pose reasoning skills for year 1 pupil. Review of European Studies, 5(4), 82.

Bell, S. (2010). Project-based learning for the 21st century: Skills for the future. The Clearing House, 83(2), 39-43.

Buck Institute for Education. (2017). Why Project Based Learning? Retrieved from https://www.pblworks.org/why-project-based-learning.

Christina, L. V., \& Kristin, F. (2016). Efektivitas Model Pembelajaran Tipe Group Investigation (GI) dan Cooperative Integrated Reading and Composition (CIRC) Dalam Meningkatkan Kreativitas Berpikir Kritis dan Hasil Belajar IPS Siswa Kelas 4. Scholaria: Jurnal Pendidikan dan Kebudayaan, 6(3), 217-230.

Clark, V. L. P., \& Creswell, J. W. (2015). Understanding Research: A Consumer's Guide (2 ed.). New York: Pearson Education.

Geurts, J., \& Meijers, F. (2009). Vocational education in The Netherlands: In search of a new identity. International Handbook of Education for the Changing World of Work (pp. 483-497). Springer.

Habók, A., \& Nagy, J. (2016). In-service teachers' perceptions of project-based learning. SpringerPlus, 5(1), 83.

Han, S., \& Bhattacharya, K. (2001). Constructionism, learning by design, and project based learning. Emerging perspectives on learning, teaching, and technology. Retrieved from: https://www.academia.edu/download/30758299/design.pdf.

Herman, T. (2007). Pembelajaran berbasis masalah untuk meningkatkan kemampuan berpikir matematis tingkat tinggi siswa sekolah menengah pertama. Educationist, 1(1), 47-56.

Jaafar, S., \& Anita, S. N. (2002). Penguasaan kemahiran generik dalam memenuhi kehendak pasaran kerja: kajian dikalangan pelajar semester akhir Diploma Kejuruteraan di Politeknik Port Dickson. Dissertation. Batu Pahat: Kolej Universiti Teknologi Tun Hussein Onn Malaysia.

Johnson, B., \& Christensen, L. (2008). Educational research: Quantitative, qualitative, and mixed approaches. Sage Publishing.

Kim, H.-Y. (2013). Statistical notes for clinical researchers: assessing normal distribution (2) using skewness and kurtosis. Restor Dent Endod, 38(1), 52-54.

Li, L. (2015). Project-based learning in electronic technology: a case study. European Journal of Engineering Education, 40(5), 499-505.

Matore, M. I. M., \& Khairani, A. Z. (2014). Mengenal Pasti Cabaran Pelajar Politeknik Di Malaysia Menerusi Model Rasch. Journal of Quality Measurement and Analysis, 10(1), 59-74.

Norhafezah, Y., Rosna, A., Hasniza, N., Fauziah, A., Sarimah, S., \& Wan Zalina, W. (2011). PBL project reflection: Challenges in communicating change. Pertanika Journal of Social Sciences and Humanities, 19(2), 335-348.

Omar, A., Taib, N. F., \& Basri, I. S. (2012). Project-Based Learning: English Carnival in Universiti Kuala Lumpur-Malaysia France Institute. The English Teacher, 41(1), 27.

Othman, N. A., Abdullah, S. R. S., Takriff, M. S., Rahman, N. A., Kofli, N. T., Ismali, M., \& Hassan, S. Z. (2015). Achievement of programme outcomes through integrated project as an innovative approach from a teaching and learning perspective. Journal of Engineering Science and Technology, Special Issue on UKM Teaching and Learning Congress 2013, 61-73.

Rahman, M. B. H. A., Daud, K. A. M., Jusoff, K., \& Ghani, N. A. A. (2009). Project Based Learning (PjBL) Practices at Politeknik Kota Bharu, Malaysia. International Education Studies, 2(4), 140. 
Rambely, A. S., Ahmad, R., Majid, N., M-Suradi, N., Din, U., A-Rahman, I., . . Abu-Hanifah, S. (2013). Project-Based Activity: Root of Research and Creative Thinking. International Education Studies, 6(6), 66.

Sadrina, S., \& Mustapha, R. (2017). The Evaluation of Project-Based Learning at the Mechanical Engineering Department, Polytechnic Malaysia: A Prosess Dimension Assessment. CIRCUIT: Jurnal Ilmiah Pendidikan Teknik Elektro, 1(1).

Sauffie, N. F. B. M. (2015). Technical and Vocational Education Transformation in Malaysia: Shaping the Future Leaders. Journal of Education and Practice, 6(22), 85-89.

See, Y. G., \& Rashid, A. M. (2015). The Effect of Project Based Learning on Level of Content Knowledge of Pre-Vocational Subject. Mediterranean Journal of Social Sciences, 6(6 S4), 369.

Singh, P., Abdul Ghani, P., \& Teoh, S. (2009). Quantitative data analysis for novice researchers. Malaysia: Primera Publishing.

Hie, T. S., Mahadhir, M., \& Banggan, J. M. (2014). The supervisor factor and undergraduates' confidence in completing their final year project. Retrieved from: https://www.tarc.edu.my/tic-conference/tic2008/abstract/No\%2087FA.pdf.

Yassin, S. M., Baharom, S., \& Yahaya, A. (2010). Exploring PBL: An Action Research Project Among Pre-Service Teachers. Paper presented at the PBL 2010 International Conference. São Paulo, Brazil.

Yeop, M. A. (2012). Kesan pendekatan pembelajaran berasaskan projek berteraskan teknologi terhadap pencapaian dan penerimaan pelajar. Tanjung Malim: Universiti Pendidikan Sultan Idris.

Yunos, J. B. M. (2008). Technical \& vocational education \& training (TVET) from Malaysia perspective. Paper presented at the 2nd International TT-TVET EU-AsiaLink project meeting, VEDC Malang. 
